This is an accepted manuscript of an article published by Taylor \& Francis in Journal of Interprofessional Care October 2016, available online:

https://www.ncbi.nlm.nih.gov/pubmed/27705011 


\section{SHORT REPORT}

\section{Interprofessional education in maternity services: Is there evidence to support policy?}

\section{Authors:}

Nigel Davies, *

Professor of Healthcare Leadership and Workforce Development, University of Bedfordshire, Luton, UK

Simon Fletcher,

Research Associate, Kingston University and St George's, University of London, UK

Scott Reeves,

Professor of Interprofessional Research, Kingston University and St George's, University of London, UK

\section{* Correspondence:}

Nigel Davies

Faculty of Health and Social Sciences

University of Bedfordshire

Putteridge Bury Campus

Hitchin Road

Luton, LU2 8PE, UK

Email: nigel.davies@beds.ac.uk

Running Head: IPE in maternity services

Word Count: 1088 (excluding Abstract, References and Figures); 2135 overall total.

Key Words: $\quad$ Maternity, Obstetrics, interprofessional education, systematic review 
IPE in maternity services

\title{
Interprofessional Education in Maternity Services: Is there evidence to support policy?
}

\begin{abstract}
Against a backdrop of poor maternity and obstetric care, identified in the Morecambe Bay Inquiry, the UK government has recently called for improvements and heralded investment in training. Given the complex mix of professionals working closely together in maternity services addressing the lack of joined up continuing professional development (CPD) is necessary. This led us to ask whether there is evidence of IPE in maternity services. As part of a wider systematic review of IPE we searched for studies related to CPD in maternity services between May 2005 and June 2014. 206 papers were identified with 24 papers included after initial screening. Further review revealed only eight papers related to maternity care none of which met the inclusion criteria for the main systematic review. The main reasons for non-inclusion included weak evaluation, a focus on undergraduate IPE and papers referring to paediatric/neonatal care only. Fewer papers were found than anticipated given the number of different professions working together in maternity services. This gap suggests further investigation is warranted.
\end{abstract}

(Abstract: 168 words)

Running Head: IPE in maternity services

Word Count: 1088 (excluding Abstract, References, Table and Figure); 2135 overall total.

Key Words: $\quad$ Maternity; Obstetrics; interprofessional education; systematic review 
IPE in maternity services

\section{Introduction}

The UK government's Secretary of State for Health has recently called for improvements in the quality of maternity care (Department of Health, 2015) to improve safety for mothers and babies and reduce the number of stillbirths, neonatal and maternal deaths by 2030 . One of the pledges is that investment is to roll out training packages so staff have the skills and confidence to deliver safe care. This announcement comes against a backdrop of examples of poor care, public concerns and a public inquiry (Kirkup, 2015b) into failings in maternity services in the Morecambe Bay area in the North-West of England. The chair of the Morecambe Bay inquiry has suggested that one of the reasons for the failures was the lack of 'joined up' continuing professional development (Kirkup, 2015a).

\section{Background}

Interprofessional education (IPE) is widely acknowledged as being beneficial for improved patient outcomes across a variety of settings with improved collaboration and teamwork seen as key factors (Hammick, Freeth, Koppel, Reeves, \& Barr, 2007). Kirkup (2015a) believed that many of the problems in the maternity unit at Morecambe Bay stemmed from poor team working, and other issues went unrecognised for too long partly because of it. He believed that the lack of trust between different professional groups, which then led to a complete breakdown of working relationships between obstetricians, midwives and paediatricians was the origin for the failings in care. This interpretation is not new or isolated to this Inquiry. For example, both the UK confidential enquiries and Australian reports on maternal deaths respectively have found one facet of substandard care to be the lack of interprofessional collaboration (Haller et al., 2008). 
IPE in maternity services

IPE, especially in relation to continuous professional development (CPD), may help to foster trust between professionals and therefore help to improve care. This may be particularly pertinent in maternity care, as a complex mix of different professional groups work closely together; typically including midwives, obstetricians, paediatricians, anaesthetists, neonatal nurses, operating department practitioners, sonographers and physiotherapists.

Different professions often have different aims and values which others may not sufficiently understand or be aware of. In Morecambe Bay, Kirkup (2015a) found this to be a significant concern with poor team working clearly undermining safe and effective care. Maternity services is one of the riskiest health areas suggesting lessons should be drawn from other high risk enterprises where team working during training is routinely included.

The current policy interest and endorsement of IPE in maternity services following the Morecambe Bay Inquiry led us to ask whether there is evidence of IPE happening for professionals providing maternity care services and what the quality of this evidence is.

\section{Methods}

An update systematic review of IPE (Reeves et al., 2014) has recently been completed under the auspices of the Best Evidence Medical and Health Professional Education Group. This review searched for relevant IPE studies from May 2005 to June 2014 using MEDLINE, the Cumulative Index of Nursing and Allied Health literature (CINAHL), the British Education Index (BEI) and the Applied Social Sciences Index and Abstracts (ASSIA) databases. This search identified 3387 papers.

A supplementary search of the results of this review was undertaken specifically in respect of maternity services. The following research questions guided this subsidiary review: 
IPE in maternity services

- Is there evidence of IPE happening for professionals providing maternity care services?

- What is the quality of this evidence?

The titles and abstracts of papers contained in the database generated for the main IPE review were searched to identify papers where there was evidence of IPE in maternity services. The search terms used are shown in Figure 1. The relevance to maternity services CPD and quality of the papers was then assessed based on criteria set out in the protocol (Reeves et al., 2014).

\section{Results}

206 papers were initially identified, with 24 papers included after initial screening, however, none of these papers met the methodological rigor and quality of information criteria for inclusion in the main systematic review. The search results are summarised in Figure 1.

\section{[INSERT FIGURE 1 ABOUT HERE]}

The 24 papers included after the initial screening had an international spread reporting research in North America $(n=13)$, Europe $(n=7)$ and Australia $(n=4)$. However, only eight papers dealt specifically with maternity care and included reports of IPE initiatives. These eight papers (see Table 1) report high fidelity simulation related to maternity emergency situations $(n=4)$, initiatives to improve communication or psycho-social skills $(n=3)$ and other specific clinical skills $(n=1)$. The main reasons for non-inclusion at this stage were the papers' focus on undergraduate IPE $(n=4)$, paediatric or neonatal care rather than maternity services $(n=10)$, and other reasons $(n=5)$, such as focussing on antenatal chronic illness management in primary care. 


\section{[INSERT TABLE 1 ABOUT HERE]}

\section{Discussion}

As noted above, only eight papers focussing on IPE for maternity services as advocated by Kirkup (2015a) were found - a figure which is less than would be anticipated given the number of different professions working together in maternity services. This would suggest that either IPE in maternity is not happening or education initiatives are not being studied, evaluated or reported. This gap would suggest further investigation is warranted given the risky nature of maternity services and the increasing use of learning strategies borrowed from the aviation industry (Haller et al., 2008). Indeed the chair of the recent Morecambe Bay Inquiry (Kirkup, 2015b) has stated that continuing IPE should take place to address safety and teamwork issues in what is a high risk speciality in the health service.

Despite the lack of research specific to maternity services, much of the evidence for IPE from other clinical specialities (see Hammick et al., 2007) is likely to be pertinent and supports the concept of IPE in maternity care and current policy. However, research taking into consideration the specific contexts and professional dynamics of maternity services would provide better insight into how this policy should be implemented in practice.

\section{Concluding comments}

Improving the quality of maternity services is high on the agenda of the UK government (Department of Health, 2015; National Maternity Review, 2016), with investment in education appearing amongst the recommendations to address poor performance. This review has shown that currently there is little rigorous evidence of the effectiveness of IPE in maternity services and that this is due to both a lack of published studies and the weak quality of those that do exist. Further research is needed to address this so that resources 
IPE in maternity services

can be channelled appropriately and that education initiatives which are relevant, appropriate and acceptable to all the interested professional groups can be implemented'. 


\section{Acknowledgements}

The authors wish to acknowledge collaboration of colleagues in the original review specifically: Prof. Ivan Birch, Dr. Sylvain Boet, Dr Simon Fletcher, Dr. Simon Kitto, DrAngus McFadyen, Dr Ferruccio Pelone, and Dr. Josette Rivera.

\section{Declaration of Interest}

The authors report no conflicts of interest. The authors alone are responsible for the content and writing of the article.

\section{References}

Burke, C., Grobman, W., \& Miller, D. (2013). Interdisciplinary collaboration to maintain a culture of safety in a labor and delivery setting. The Journal of Perinatal \& Neonatal Nursing, 27(2), 11323; quiz 124-5. http://doi.org/10.1097/JPN.0b013e31828cbb2a

Daniels, K., Lipman, S., Harney, K., Arafeh, J., \& Druzin, M. (2008). Use of simulation based team training for obstetric crises in resident education. Simulation in Healthcare : Journal of the Society for Simulation in Healthcare, 3(3), 154-160. http://doi.org/10.1097/SIH.0b013e31818187d9

Department of Health. (2015). New ambition to halve rate of stillbirths and infant deaths. Retrieved November 15, 2015, from https://www.gov.uk/government/news/new-ambition-to-halve-rateof-stillbirths-and-infant-deaths

Haller, G., Morales, M., Pfister, R., Garnerin, P., Chipp, P., Guillemot, V., ... Kern, C. (2008). Improving interprofessional teamwork in obstetrics: A Crew Resource Management based training programme. Journal of Interprofessional Care, 22(5), 545-548. http://doi.org/10.1080/13561820802038831

Hammick, M., Freeth, D., Koppel, I., Reeves, S., \& Barr, H. (2007). A best evidence systematic review of interprofessional education: BEME Guide no.9. Medical Teacher, 29(8), 735-751.

Kirkup, B. (2015a). Morecambe Bay will happen again if underlying causes aren't eradicated. Retrieved July 14, 2015, from http://m.hsj.co.uk/5087873.article

Kirkup, B. (2015b). The Report of the Morecambe Bay Investigation. London: The Stationery Office. Retrieved from https://www.gov.uk/government/uploads/system/uploads/attachment_data/file/408480/474 
IPE in maternity services

87_MBI_Accessible_v0.1.pdf

MacEachin, S. R., Lopez, C. M., Powell, K. J., \& Corbett, N. L. (2009). The Fetal Heart Rate Collaborative Practice Project. Journal Perinatal Neonatal Nursing, 23(4), 314-323. http://doi.org/10.1097/JPN.0b013e3181a1bf07

National Maternity Review. (2016). Better Births: Improving outcomes of maternity services in England (Chair Baroness Cumberledge). London. Retrieved from https://www.england.nhs.uk/wp-content/uploads/2016/02/national-maternity-reviewreport.pdf

Posmontier, B., Montgomery, K., Smith Glasgow, M. E., Montgomery, O. C., \& Morse, K. (2012). Transdisciplinary Teamwork Simulation in Obstetrics-Gynecology Health Care Education. Journal of Nursing Education, 51(3), 176-179. http://doi.org/10.3928/01484834-20120127-02

Reeves, S., Barr, H., Birch, I., Boet, S., Davies, N., Kitto, S., ... Rivera, J. (2014). A systematic review of the impact of interprofessional education on health and social care practitioners, professional practice, patient/client health and social care outcomes (Protocol). Retrieved from http://bemecollaboration.org/Reviews+In+Progress/BEME+Guide+9+Update/

Rego, P., Lyon, P., \& Watson, M. (2011). The impact of maternity crisis resource management training. British Journal of Midwifery, 19(5), 315-323.

Saxell, L., Harris, S., \& Elarar, L. (2009). The Collaboration for Maternal and Newborn Health: Interprofessional Maternity Care Education for Medical, Midwifery, and Nursing Students. Journal of Midwifery and Women's Health, 54(4), 314-320. http://doi.org/10.1016/j.jmwh.2009.03.017

Solomon, P., \& Salfi, J. (2011). Evaluation of an interprofessional education communication skills initiative. Education for Health, 24(2), 616. Retrieved from http://ezproxy.net.ucf.edu/login?url=http://search.ebscohost.com/login.aspx?direct=true\&db= psyh\&AN=2011-19715-005\&site=edslive\&scope=site\nhttp://ezproxy.net.ucf.edu/login?url=http://search.ebscohost.com/login.asp

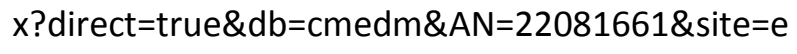


Figure 1

\section{Search results}

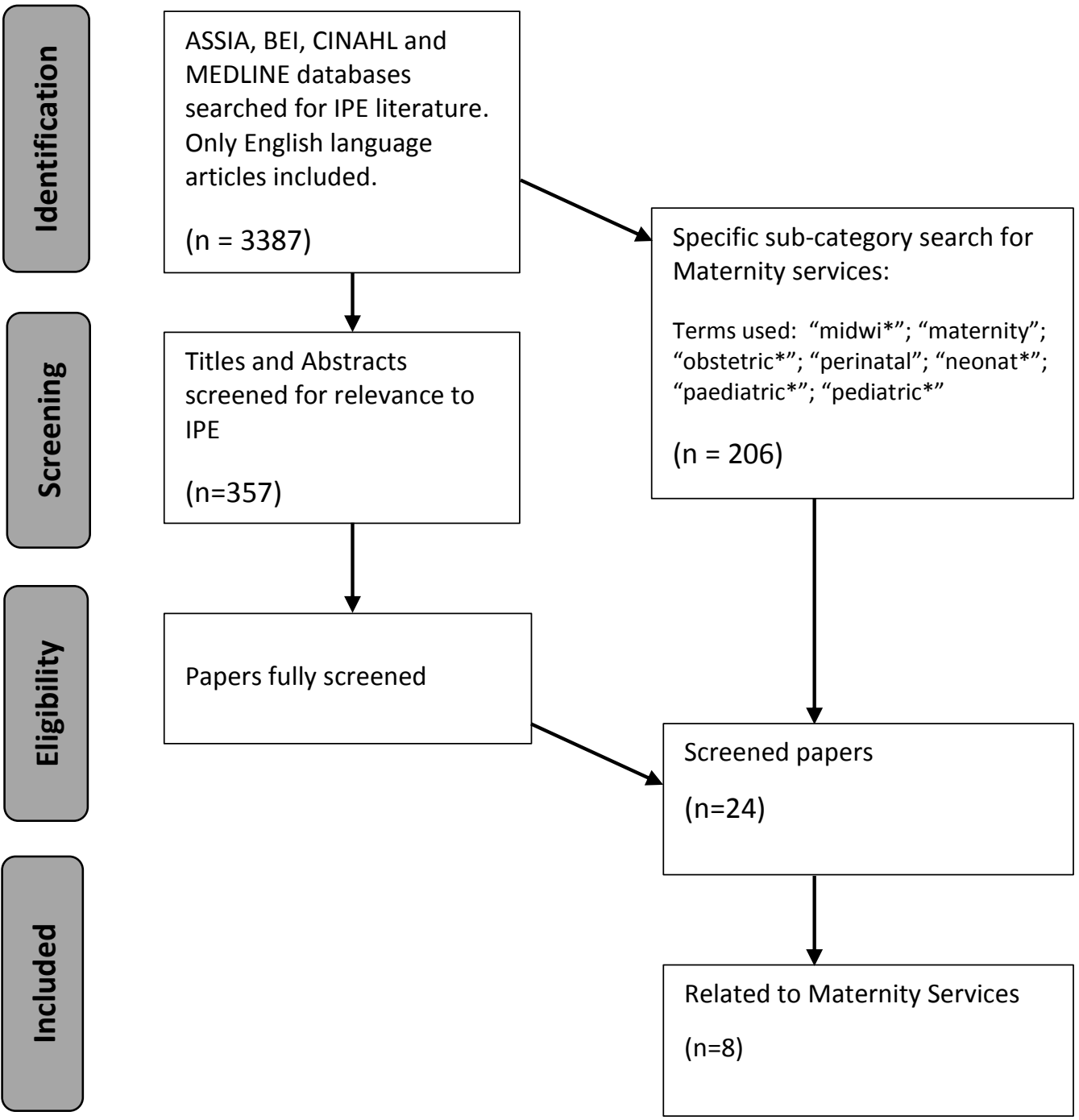


Table 1: Overview of included IPE studies undertaken in maternity services

\begin{tabular}{|c|c|c|c|c|}
\hline $\begin{array}{l}\text { Lead author/year of } \\
\text { publication }\end{array}$ & Setting, Country & Sample and number & Intervention & Methodological Comments \\
\hline Burke (2013) & $\begin{array}{l}\text { University Women's } \\
\text { Hospital, Chicago, USA }\end{array}$ & $\begin{array}{l}\text { Obstetricians, midwives, } \\
\text { anaesthetists, nurses } \\
(\mathrm{n}=370)\end{array}$ & $\begin{array}{l}\text { Didactic training plus simulation exercise } \\
\text { as part of mandatory training programme } \\
\text { for doctors and nurses (midwives). }\end{array}$ & $\begin{array}{l}\text { Participant feedback is main source of } \\
\text { evaluation data, with some global outcome } \\
\text { measures linked to improvement in safety }\end{array}$ \\
\hline Daniels (2008) & $\begin{array}{l}\text { Labour and Delivery } \\
\text { ward, Stamford, USA }\end{array}$ & $\begin{array}{l}\text { Nurses, midwives, } \\
\text { obstetricians, anaesthetists } \\
(n=49)\end{array}$ & $\begin{array}{l}\text { Simulation based training for } \\
\text { interprofessional teams. Two scenarios } \\
\text { followed by a facilitated debriefing }\end{array}$ & $\begin{array}{l}\text { Paper reports evaluation only of the } \\
\text { medical residents in the group. All } \\
\text { simulations were videotaped. }\end{array}$ \\
\hline Haller (2008) & $\begin{array}{l}\text { University affiliated } \\
\text { hospital, Geneva, } \\
\text { Switzerland }\end{array}$ & $\begin{array}{l}\text { Nurses, midwives, } \\
\text { technicians, doctors }(n=239)\end{array}$ & $\begin{array}{l}\text { Used a CRM (Crew Resource Management) } \\
\text { approach based on commercial aviation } \\
\text { methods. Produced a film showing errors } \\
\text { and included role play but not simulation }\end{array}$ & $\begin{array}{l}\text { The paper only reports participants' } \\
\text { satisfaction with training }\end{array}$ \\
\hline MacEachin (2009) & $\begin{array}{l}\text { Kaiser Permanente } \\
\text { system, California, US }\end{array}$ & $\begin{array}{l}\text { Nurses, certified midwives } \\
\text { and physicians as trainers } \\
\text { (offered to all staff, } n=1838 \text { ) }\end{array}$ & $\begin{array}{l}\text { Fetal monitoring training programme. IP } \\
\text { collaboration to create multi-media } \\
\text { training package; IP champions (train the } \\
\text { trainer) then roll out across system }\end{array}$ & $\begin{array}{l}\text { Evaluation is based on feedback on training } \\
\text { programme and safety perceptions. Data } \\
\text { from baseline } 2002 \text { and four years post } \\
\text { intervention. }\end{array}$ \\
\hline Posmontier (2012) & Philadelphia, US & $\begin{array}{l}\text { Obstetricians, nurse } \\
\text { practitioners, nurse } \\
\text { students, physician } \\
\text { assistants }(n=35)\end{array}$ & $\begin{array}{l}\text { Teamwork simulation of an obstetric } \\
\text { emergency }\end{array}$ & $\begin{array}{l}\text { Pre-test/ post-test measures were self- } \\
\text { report by students. Findings show that } \\
\text { intervention enhanced mutual support and } \\
\text { communication but no significant increase } \\
\text { in attitudes for structure, situation } \\
\text { monitoring, and leadership. }\end{array}$ \\
\hline Rego (2011) & Queensland, Australia & $\begin{array}{l}\text { Obstetricians and midwives } \\
\text { ( } \mathrm{n}=195,77 \% \text { midwives, } 23 \% \\
\text { medics) } \\
\text { Follow-up with } 20 \text { midwives } \\
\text { and } 10 \text { Drs) }\end{array}$ & $\begin{array}{l}\text { Maternity Crisis Resource Management } \\
\text { (MaCRM) programme. } 2 \text { day course } \\
\text { including didactic teaching, skills stations } \\
\text { (number of potential crises) and simulated } \\
\text { emergencies. }\end{array}$ & $\begin{array}{l}\text { Evaluation included learner satisfaction with } \\
\text { training; learning uptake, transfer of } \\
\text { learning to workplace and outcomes. } \\
3 \text { months post-training a sample of } \\
\text { midwives and doctors were followed up } \\
\text { with further interviews with supervisors to } \\
\text { balance effects of self-reporting. }\end{array}$ \\
\hline Saxell ( 2009) & Vancouver, Canada & $\begin{array}{l}\text { Medical, Midwifery and } \\
\text { Nursing Undergraduate } \\
\text { Students ( } n=467 \text { ) }\end{array}$ & $\begin{array}{l}3 \text { different programmes targeted at } \\
\text { students interested in maternity care (incl. } \\
\text { normal labour and birth workshop; student }\end{array}$ & Only reports student satisfaction \\
\hline
\end{tabular}




\begin{tabular}{|c|c|c|c|c|}
\hline Lead author/year of & Setting, Country & Sample and number & Intervention & Methodological Comments \\
\hline & & & $\begin{array}{l}\text { Doula support program; and a student-led } \\
\text { maternity care club. }\end{array}$ & \\
\hline Solomon (2011) & $\begin{array}{l}\text { McMaster University, } \\
\text { Ontario, Canada }\end{array}$ & $\begin{array}{l}\text { Undergraduate students } \\
\text { (incl. medics, nurses, } \\
\text { therapists, midwifes) ( } n=96)\end{array}$ & $\begin{array}{l}\text { Program evaluation of IPE } 3 \mathrm{hr} \text { team based } \\
\text { communications skills initiative. }\end{array}$ & $\begin{array}{l}\text { Evaluation based only on student } \\
\text { satisfaction plus scales measuring readiness } \\
\text { for IP work }\end{array}$ \\
\hline
\end{tabular}

